Case report

\title{
Pericardial mesothelioma presenting as systemic lupus erythematosus
}

\author{
L. McGUIGAN AND A. FLEMING \\ From the Department of Rheumatology, Prince Henry Hospital, Little Bay, Sydney, Australia
}

SUMMARY A case of mesothelioma of the pericardium with many features of systemic lupus erythematosus (SLE) is described. We stress that satisfaction of the American Rheumatism Association's classification criteria for SLE does not confirm the diagnosis, even though their diagnostic sensitivity and specificity has recently been improved.

The recent revision of the American Rheumatism Association's (ARA) criteria for SLE has increased their diagnostic sensitivity and specificity. ${ }^{1}$ It should be remembered, however, that there are other conditions which may satisfy these classification criteria.

Our case of mesothelioma of the pericardium, which not only satisfied several clinical but also a number of serological criteria for SLE, illustrates this diagnostic problem.

\section{Case history}

A 56-year-old married Caucasian woman was admitted to hospital on three separate occasions during the 10-month course of an illness which ultimately led to her death. She was first admitted on 25 December 1980 with a three-week history of right-sided pleuritic chest pain, synovitis of both wrists, patchy scalp alopecia, mouth ulcers, and Raynaud's phenomenon of both hands. She had lost $15 \mathrm{~kg}$ in weight without dieting during 1980.

Examination at the time of admission revealed dullness to percussion and crepitations at the right lung base, fever $\left(39^{\circ} \mathrm{C}\right)$, a macular rash in both axillae, and synovitis of the wrists. A chest radiograph (Fig. 1) showed small bilateral pleural effusions. Other investigations are shown in Table 1. A presumptive diagnosis of bronchopneumonia with pleural effusion was made. Antibiotic therapy with penicillin was begun with symptomatic but no radiological improvement. However, despite this, she was discharged on 14 January 1981.

Accepted for publication 17 October 1983.

Correspondence to Dr A. Fleming
Over the next three months the patient developed severe myalgia and recurrent chest pain. She was given prednisone $15 \mathrm{mg} / \mathrm{day}$, as a diagnosis of SLE was thought likely. However, she failed to improve on this dose and was admitted to another hospital on 25 May 1981. At that time she had an erythematous photosensitive rash in a malar distribution, patchy scalp alopecia, and bilateral basal crepitations. Investigations were repeated (Table 1). The chest radiograph was unchanged. A diagnosis of SLE was made. The patient satisfied seven of the original ARA criteria for $\mathrm{SLE}^{2}$ by this time. She was started on prednisone $60 \mathrm{mg} /$ day with dramatic symptomatic

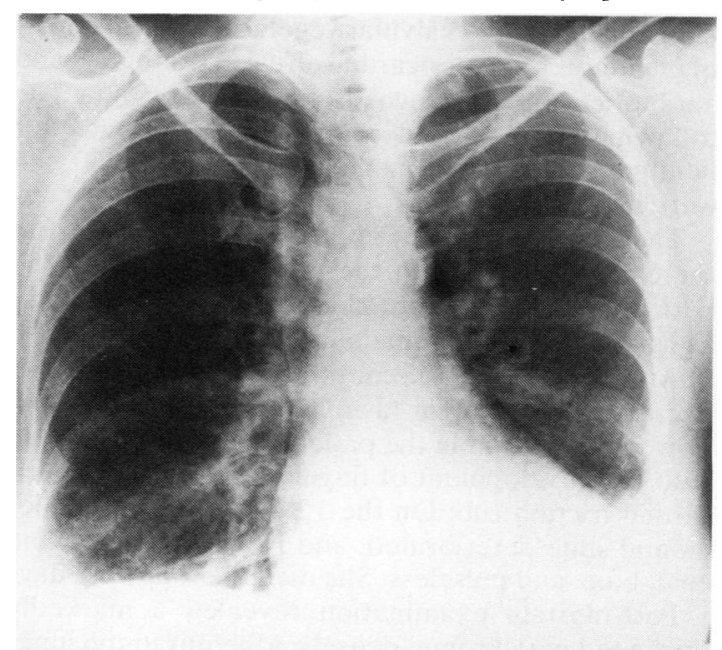

Fig. 1 Chest radiograph on initial admission, showing small bilateral pleural effusions. 
Table 1 Haematology and immunology data obtained during the three admissions

\begin{tabular}{|c|c|c|c|}
\hline & $\begin{array}{l}\text { 1st admission, } \\
\text { December } 1980\end{array}$ & $\begin{array}{l}\text { 2nd admission, } \\
\text { May } 1981\end{array}$ & $\begin{array}{l}\text { 3rd admission, } \\
\text { September } 1981\end{array}$ \\
\hline Haemoglobin (g/dl) & $14 \cdot 3$ & $9 \cdot 2$ & $12 \cdot 1$ \\
\hline Leucocyte count $\left(\times 10^{9} / 1\right)$ & $22 \cdot 3$ (neutrophils $95 \%$ ) & $13 \cdot 7$ (neutrophils $84 \%$ ) & $20 \cdot 2$ (neutrophils $88 \%$ ) \\
\hline $\operatorname{ESR}(\mathrm{mm} / \mathrm{h})$ & 65 & 112 & 58 \\
\hline Creatinine $(\mathrm{mmol} / \mathrm{l})$ & 0.07 & 0.05 & 0.06 \\
\hline ANA (rat liver) & $1: 10^{*}$ speckled & $1: 10^{*}$ speckled & $1: 10^{*}$ speckled \\
\hline FARR assay $(\mathrm{n}<30 \%)$ & $18.9 \%$ & $17 \cdot 6 \%$ & $12 \cdot 0 \%$ \\
\hline Rh factor (RA latex) & Negative & Negative & Negative \\
\hline Immune complexes $(\mathrm{n}<20 \%)$ & $37 \%$ & $60 \%$ & $50 \%$ \\
\hline $\mathrm{CH}_{50}$ (normal 68-138) & 44 & 75 & 113 \\
\hline Lymphocytotoxins (n $0-5$ ) & 27 & 62 & - \\
\hline VDRL & $\dagger$ Reactive (BFP) & - & †Reactive (BFP) \\
\hline Blood Cultures & Negative $(\times 2)$ & - & Negative $(\times 6)$ \\
\hline
\end{tabular}

${ }^{*} 1: 10=$ Weak positive result.

$\dagger \mathrm{BFP}=$ Biologically false positive.

relief and was discharged on 28 June 1981 taking prednisone $25 \mathrm{mg} /$ day.

She remained well until September 1981, when the myalgia recurred. She had also developed multiple nail-fold infarcts and splinter haemorrhages, but there were no cardiac murmurs or febrile episodes. She was admitted for a third time, reinvestigated (Table 1) and started on azathioprine $100 \mathrm{mg} /$ day and prednisone $60 \mathrm{mg} /$ day, as the vasculitic lesions were thought to be manifestations of SLE.

Again there was clinical improvement until on 27 September 1981 she became febrile $\left(39 \cdot 5^{\circ} \mathrm{C}\right)$, dyspnoeic, and hypoxic $\left(\mathrm{PAO}_{2} 50 \mathrm{mmHg}\right.$ on room air). $\mathrm{A}$ chest radiograph showed a pulmonary infiltrate with cardiomegaly. Blood cultures were negative. A twodimensional echocardiogram showed a large pericardial effusion but no valvular vegetations. A diagnosis of pneumonia and pericardial effusion was made, and antibiotics and hydrocortisone were begun. The following day, she developed a profound left hemiparesis. Lumbar puncture and cerebral CT scan were normal, however.

The antibiotic therapy improved the dyspnoea, but there was no change in the neurological state. The pericardial fluid was not drained, as there were no signs of cardiac tamponade.

Antibiotics were discontinued after one month because of an allergic rash. Thereafter there was a slow deterioration in the patient's general condition, with the development of finger clubbing and a pericardial friction rub. On the 12 November 1981 her mental state deteriorated, and her left foot became cold, blue, and pulseless. She died the following day.

Post-mortem examination revealed a markedly thickened pericardium densely adherent to the lungs and diaphragm. There were several warty vegetations on the atrial surface of the mitral valve $(0 \cdot 1-0 \cdot 3$ $\mathrm{cm}$ in diameter) but there was no valve ulceration or deformation. The right common carotid artery showed a laminated thrombus completely occluding the lumen. Brain examination showed an infarction of the right insula and right cerebellar cortex.

Gram stain and histological examination of the valve vegetations revealed fibrin, neutrophils, and macrophages but no organisms. The unexpected finding was in the pericardium, where there were nests of tumour cells with bizarre nuclei and occasional giant tumour cells (Fig. 2). Sections of the carotid showed tumour infiltration in the wall and within the thrombus (Fig. 3). There was invasion of the pleura and

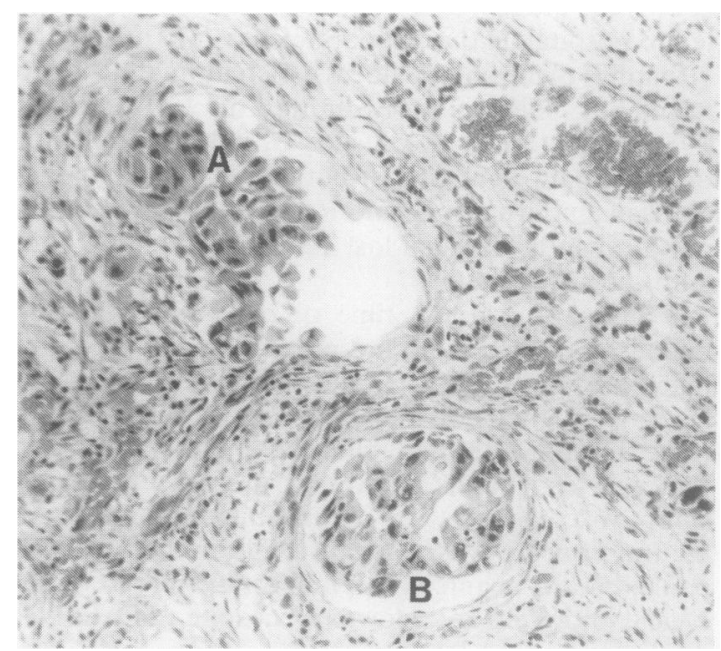

Fig. 2 Photomicrograph showing nests of tumour cells (A, $\mathrm{B})$ in the pericardial tissue. (Haematoxylin and eosin, $\times$ 115). 


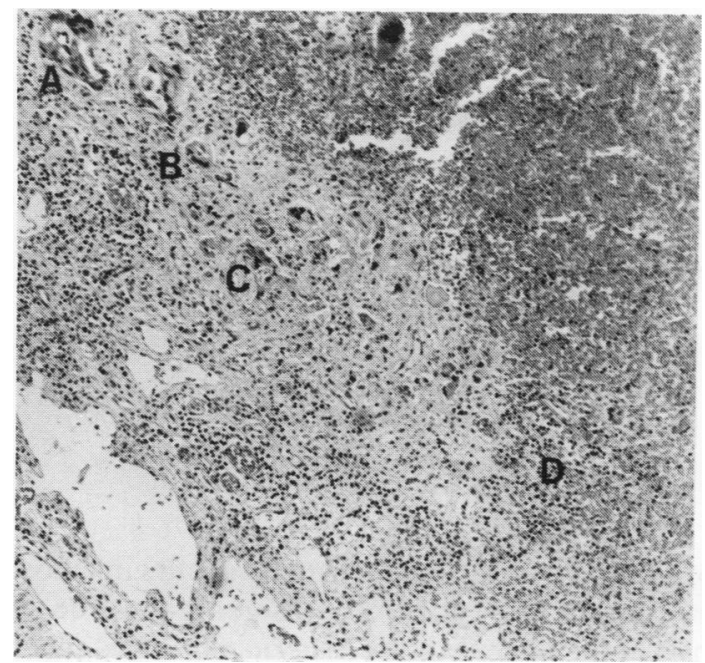

Fig. 3 Photomicrograph of the thrombosed carotid artery showing small nests of tumour cells $(\mathrm{A}, \mathrm{B}, \mathrm{C})$ in the vessel wall and edge of the thrombus (D). (Haematoxylin and eosin, $\times 60$ ).

pulmonary lymphatics. Alcian blue staining showed these tumour cells to be from a mesothelioma.

\section{Discussion}

The local pericardial and pleural manifestations of a mesothelioma have been described previously ${ }^{3}$ and are clearly demonstrated in this case. Non-bacterial thrombotic endocarditis, ${ }^{4}$ vasculitis, ${ }^{56}$ and serological abnormalities ${ }^{7}$ are recognised neoplastic complications. However, to our knowledge this is the first report of the concurrence of these clinical and laboratory features in pericardial mesothelioma. The site of the original lesion, the local and lymphatic spread, and the systemic and serological features of the malignancy resulted in a picture where SLE was a distinct diagnostic possibility.

This report highlights the fact that any disease with protean manifestations could possibly satisfy ARA criteria for SLE. In fact our case showed six of the new criteria and seven of the old. In addition other features often associated with SLE, including digital vasculitis, ${ }^{8}$ focal neurological signs, ${ }^{8}$ and depressed complement levels, ${ }^{9}$ were observed.

This case illustrates the danger of making the diagnosis of SLE when the titre of ANA is low. This is particularly relevant now that increasing numbers of patients with 'ANA negative' SLE are being reported. ${ }^{10}$

\section{References}

1 Tan E M, Cohen A S, Fries J F, et al. The 1982 revised criteria for the classification of systemic lupus erythematosus. Arthritis Rheum 1982; 25: 1271-7.

2 Cohen A S, Reynolds W E, Franklin E C, et al. Preliminary criteria for the classification of systemic lupus erythematosus. Bull Rheum Dis 1971; 21: 643-8.

3 Antman K H. Malignant mesothelioma. N Engl J Med 1980; 303: 200-2.

4 Bryan C S. Nonbacterial thrombotic endocarditis with malignant tumors. Am J Med 1969; 46: 787-93.

5 McCombs R P. Systemic allergic vasculitis. JAMA 1965; 194: $1059-64$

6 Sams W M, Harville D D, Winkelmann R K. Necrotizing vasculitis associated with lethal reticulo-endothelial diseases. $\mathrm{Br} \mathrm{J}$ Dermatol 1969; 80: 555-60.

7 Byrd W E, Matthews O P, Hunt R E. Left atrial myxoma presenting as a systemic vasculitis. Arthritis Rheum 1980; 23: 240-3.

8 Rothfield N. Clinical features of systemic lupus erythematosus. In: Kelley W N, Harris E D, Ruddy S. Sledge C B, eds. Textbook of rheumatology. Philadelphia: Saunders, 1981: 1106-32.

9 Steinberg A D. Management of systemic lupus erythematosus. In: Kelley W N, Harris E D, Ruddy S, Sledge C B, eds. Textbook of rheumatology. Philadelphia: Saunders, 1981: 1133-50.

10 Rothschild B M, Jones J V, Chesney C, et al. Relationship of clinical findings in systemic lupus erythematosus to seroreactivity. Arthritis Rheum 1983; 26: 45-51. 